\title{
AC 2007-2502: A HOLISTIC REVIEW OF MECHANICAL DESIGN CURRICULUM IN AN ENGINEERING TECHNOLOGY PROGRAM
}

\section{Jyhwen Wang, Texas A\&M University}

Jyhwen Wang joined the Department of Engineering Technology and Industrial Distribution at Texas A\&M University in 2001 after working 10 years as a researcher and R\&D manager in steel industry. He teaches mechanical design applications and his research interest is in the areas of mechanical design and material processing technology. He received his $\mathrm{Ph}$. D. degree in mechanical engineering from Northwestern University.

\section{Richard Harris, Sandia National Laboratories}

Rick Harris is Manager of Mechanical Design within the Weapons Engineering division of Sandia National Laboratories in Albuquerque, New Mexico. Rick has twenty two years of experience in engineering design, build, test, modeling and simulation, as well as software development. He is experienced in organizational leadership, project and program management, and information systems development. Rick has a special interest in developing organizations to align with the needs of the business invigorated with professional development of the staff. Rick has a Mater's degree in mechanical engineering from the University of Michigan. 


\title{
A Holistic Review of Mechanical Design Curriculum in An Engineering Technology Program
}

\begin{abstract}
In most of the mechanical and manufacturing engineering technology programs, mechanical design is a critical course for students to acquire the knowledge and skill in design of mechanical components and systems. While the course contents generally include important topics, such as failure theories and machine elements, a holistic mechanical design education should also address the interdependency between various subjects related to mechanical design. The subject of mechanical design should be viewed as an "integrated curriculum," not an isolated course. As a result of a professional development project with the Sandia National Laboratories (SNL), the Manufacturing and Mechanical Engineering Technology (MMET) program at Texas A\&M University (TAMU) has embarked on a critical review of its mechanical design curriculum. This paper presents the collaboration between TAMU and SNL on the education development project, the on-going curriculum review of mechanical design courses, and the initial findings and recommendations for the MMET program at TAMU. The methodology in this study can be used as a continuous improvement process for engineering technology education.
\end{abstract}

\section{Introduction}

The typical mechanical engineering technology curriculum consists of a mechanical design course or sequence. Taken during the junior and/or senior years, these courses carry titles such as Mechanical Design, Machine Design, Machine Element Design, and Mechanical System Design. In this context, design means to create a component or a system to meet the desired functional requirements. Thus, the objective of the course is to provide the concepts, methodologies, knowledge, analytical skills, and decision-making techniques necessary to design mechanical parts (components), devices, and systems. Building upon the students' knowledge of statics, dynamics, and strength of materials, the course Fundamentals of Mechanical Design often focuses on the topics of design methodology, stress analysis, failure theories, and material selections. The course in machine design introduces the theories and application of machine elements such as gears, bearing, springs, fasteners.

Real-world design requires designers to have a broad knowledge base and skill set. A designer has to be able to visualize the spatial relationship of components, to use computer-aided design (CAD) tools to communicate design concepts, to specify dimensions and tolerances, and to identify appropriate processes for part manufacturing. In addition, mechanical designers are often expected to conduct stress analysis and selection materials, to estimate costs, to manage multiple projects, and to work effectively on a team. In the academic world, a cluster of knowledge is grouped into courses for efficient learning of these subjects [1]. It is clear that the task of mechanical design can only be accomplished with the knowledge and skill acquired from various courses. Thus, a capstone design course is commonly in place for students to acquire integrating experience. Efforts have been made to develop different approaches to the capstone course, and the format and the implementation of the course vary from institution to institution [2-8]. While the capstone course can better prepare students to enter the work force, the effort seems too little too late. Other than the prerequisites specified for relevant courses, a holistic 
mechanical design education should address the interdependencies between various subjects related to mechanical design.

In this paper, we first describe the existing mechanical design curriculum in the Manufacturing and Mechanical Engineering Technology (MMET) program in the Department of Engineering Technology and Industrial Distribution at Texas A\&M University (TAMU). Comparing the needs of the industry with the existing curriculum serves as a continuous improvement process. Based on a collaborative professional development project with the Sandia National Laboratories (SNL) and a survey of the MMET program constituencies, we identify the mechanical design knowledge and skill students are expected to acquire before graduation (Section 3). To improve mechanical design education, the recommended integrative mechanism and curriculum changes are discussed in Section 4. A brief conclusion is included in Section 5.

\section{Courses in Mechanical Design Curriculum}

The minimum total credit hours required for students in the ABET-accredited MMET program at TAMU is 132. Excluding the courses in communications, mathematics, physical and natural sciences, and social sciences and humanities, the technical content has 77 credits. The disciplinespecific components of the program, among other added-depth technical areas, include Mechanical Design. The courses in the mechanical design sequence are described as followings:

- ENGR 111A - Foundations of Engineering I (Mechanics Track). Introduction to the engineering profession, ethics, and disciplines; development of skills in teamwork, problem solving and design; major emphasis on computer applications and programming; visualization and CAD tools.

- ENGR 112A - Foundations of Engineering II (Mechanics Track). Continuation of ENGR 111. Topics include major emphasis on computer applications and programming and solid modeling using CAD.

- PHYS 218 - Mechanics. Mechanics for students in science and engineering. Fundamental principles of classical mechanics including kinematics, Newton's Laws, conservation of energy and momentum, oscillations and wave motion.

- ENTC 275 - Mechanics for Technologists. Forces, moments and couples in 2-D and 3-D systems, equilibrium of rigid bodies; friction and application; centroids and moment of inertia; review of particle dynamic principles; kinematics and kinetics of rigid bodies; principles of impulse-momentum and work-energy; computer use in selected areas.

- ENTC 376 - Strength of Materials. Stress and strain; elastic moduli, Poisson's ratio, torsion, bending, unsymmetrical bending, design of beams and shafts; deflection of beams; buckling of columns; materials and strength characterization laboratory tests.

- ENTC 361 - Solid Modeling and Analysis. Fundamentals of part geometry development and mechanical assembly; simple finite element analysis used to evaluate and optimize design, rapid prototyping of simple product models. 
- ENTC 363 - Mechanical Design Applications I. Principles of design of mechanical components; theories of failure; fatigue and fracture design criteria; Soderberg and Goodman diagrams; materials and their selections to engineering application; tolerance and fit, design for manufacturing and assembly.

- $\quad$ ENTC 463 - Mechanical Design Applications II. Application of principles of design to mechanical power transmission elements such as shafts, gears, rolling chains, belts, bearings, clutches and brakes; design of power transmission systems.

- ENTC 422 - Manufacturing [and Mechanical] Engineering Technology Projects. A capstone projects course utilizing a team approach to an analysis and solutions of manufacturing [and mechanical] problems.

Figure 1 shows the course sequence. The prerequisites are shown as links with arrows. Other courses that are not listed in the sequence but have significant impact in mechanical design include: ENTC 181 Manufacturing and Assembly Processes I, ENTC 206 Nonmetallic Materials, ENTC 207 Metallic Materials, ENTC 303 Fluid Mechanics and Power, ENTC 370 Thermodynamics for Technologists.

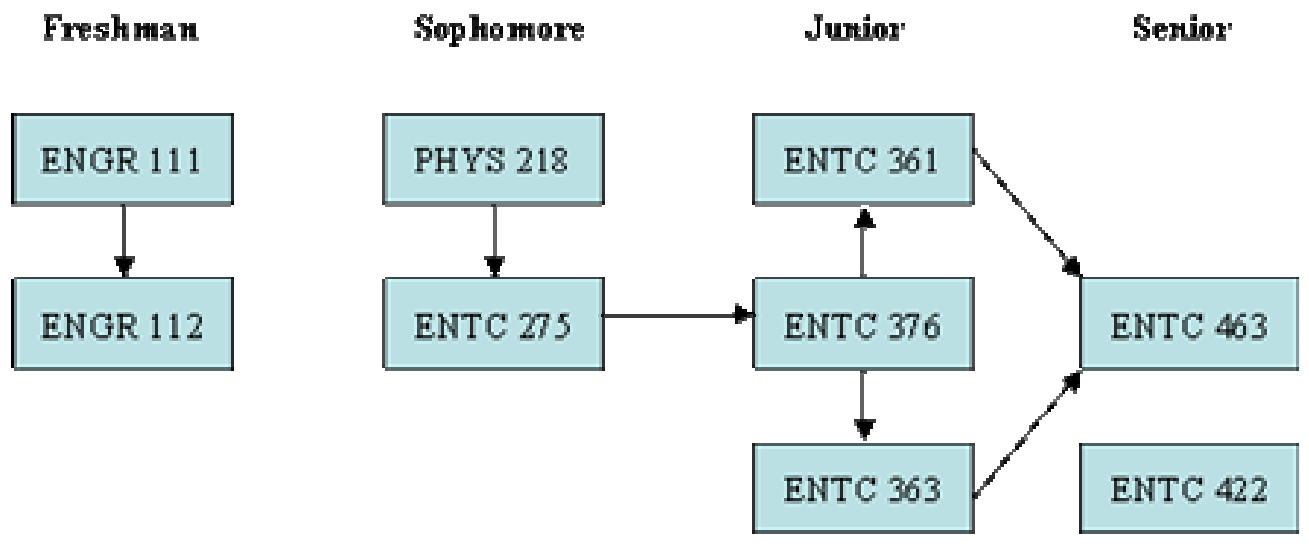

Figure 1 Courses in mechanical design technical area

\section{The Desired Attributes of Mechanical Designers}

Product quality and company competitiveness are greatly influenced by the design process and the capability of the design staff. While it is generally accepted that good processes are vital to predictable and sustainable high performance, personal capability and professional skill cannot be dismissed. In the industrial setting, attracting and retaining skillful design engineers continues to be a critical success factor for companies. Two question remain, What makes a great designer? What differentiates them from others?

In the last two years, Sandian National Laboratories and Texas A\&M have worked together to increase the knowledge and capabilities of design engineers and designer/drafters at Sandia. The professional development program consists of lectures, review sessions, and seminars in various 
mechanical design related topics, including mechanics and strength of materials, static and fatigue failure theories, geometric dimensioning and tolerancing, statistical tolerance analysis, fastener (screw/bolt) design, design methodologies and design optimization, and fundamentals of finite element analysis.

This partnership has yielded encouraging results. For example, designer/drafters without an engineering degree have gained a better understanding of strength of materials and failure criteria enabling them to successfully apply Pro/Mechanica as an analytical tool. This analysis has allowed them to evaluate their design with decreased manufacturing, assembly, and testing. In addition, the emphasis on ASME Geometric Dimensioning and Tolerancing (GD\&T) certification has resulted in 50 percent of the designers within the Sandia mechanical design department earning certification. The study required and the confidence gained through the certification process has begun to result in increased design quality. These results have encouraged SNL to continue this type of professional development, increasing the knowledge of the associated degree designer/drafters and refreshing the capabilities of the degreed engineers. From the perspective of companies, good mechanical designers should have added-depth knowledge and skill in the following areas:

- Computer-Aided Design software - With the advancement of computer hardware and software, solid modeling software tools are used extensively by designers. These tools allow the designers to produce models/drawings and to visualize parts and assemblies quickly. This capability is invaluable in meeting the need for speed in product design and development. Mastery of CAD is clearly a prerequisite to successful design, but other knowledge beyond the ability to model and produce drawings is also required.

- Geometry dimensioning and tolerancing - Designers must have a mastery of tolerance specification and analysis. Skillful designers effectively consider datum selection and design viability using tolerance analysis in the early stages of design. Later in the design process, detailed GD\&T is the cornerstone for ensuring that parts can be assembled properly.

- Manufacturing processes - Proper GD\&T decisions are influenced by knowledge of the manufacturing process capability. Knowledge of these process capabilities also allows the designers to create, evaluate, and select design options. First hand experience with basic manufacturing processes and awareness of advanced process are necessary to be an effective designer.

- Engineering mechanics - Decisions on part geometry and material affect the structural performance of the parts (e.g. stress, deflection, buckling load, natural frequency, etc.) Designers need to understand if their design will be able to meet the specified requirements. Therefore, timely evaluation is needed for designers to perform analysis using hand calculations and integrated CAD/FEA tools.

- Communication - It is rare that an individual can consistently produce great designs on their own. Therefore, at various stages of the design, communication of design is required. For example, at SNL, Peer Reviews serve as a method to identify design, 
modeling, and drafting errors. These Peer Reviews establish an organizational norm for critically reviewing designs produced by others. Because top designers perform design reviews, they must possess the ability to clearly communicate their design ideas and to offer constructive suggestions.

- Project management - A complete grasp of functional and non-functional design requirements is essential. Good designers must fully understand the design problem, interface constraints and previous successful solutions to similar problems. Effective designers must also manage their time and cost constraints. Basic project management discipline is therefore a necessary element for success.

The TAMU-SNL collaboration also leads to a critical review of the MMET mechanical design curriculum. ABET accreditation requires a continuous improvement plan to ensure the quality of the educational program. The schematic of the MMET continuous improvement process is shown in Figure 2 [9]. Loop 2 (in Figure 2) shows that the input from an Industry Advisory Committee (IAC) is one of the instruments for outcome assessment and evaluation. Based on this mechanism, a survey was designed and sent to the IAC members. In this survey, a list of mechanical design related subjects was given. The IAC members were asked to assign a score from 1 to 5 indicate the strength (from low to high) of the knowledge and skill students are expected to acquire before graduation. The survey results are summarized in Table 1.

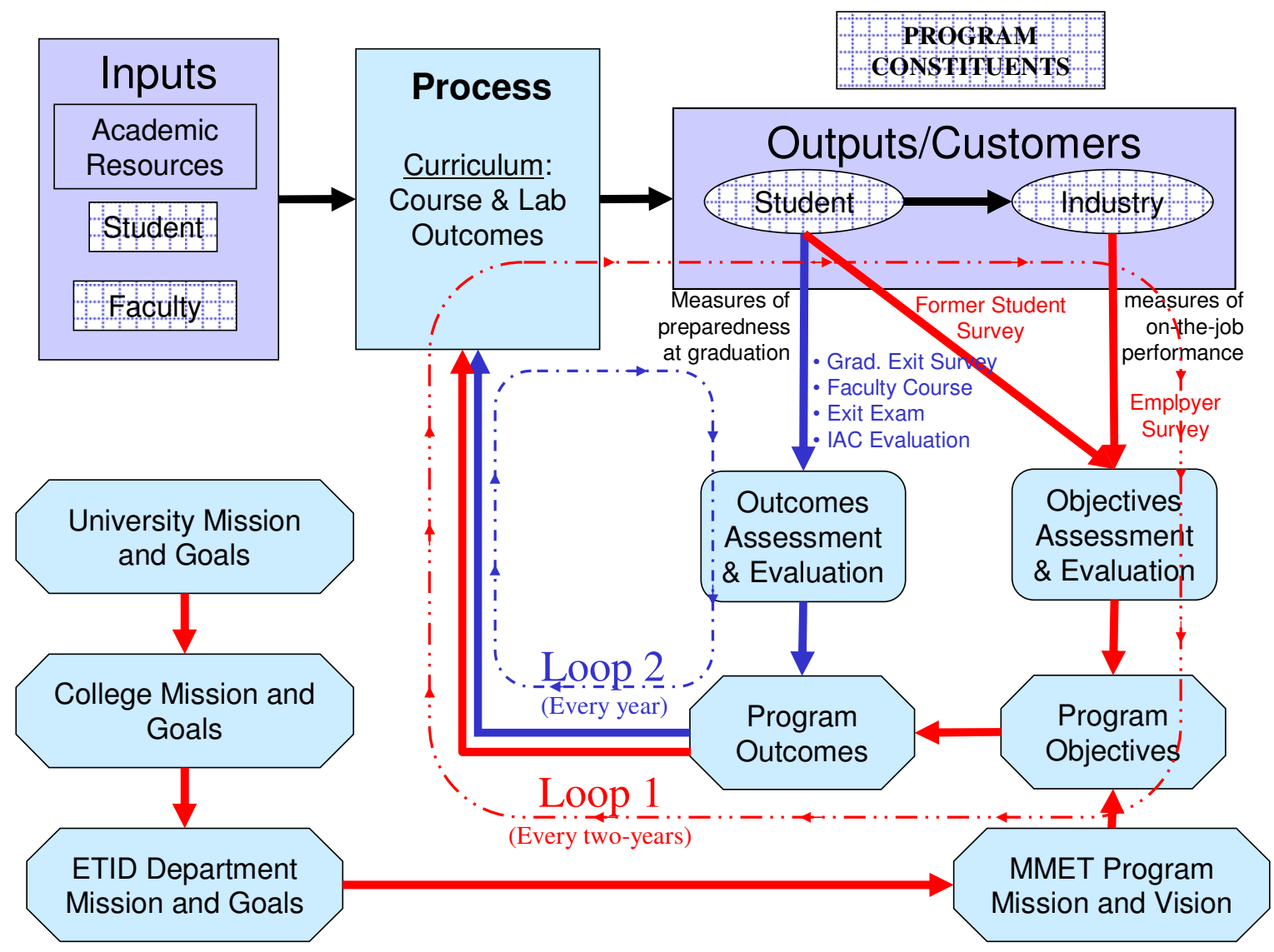

Figure 2 The MMET continuous improvement process [9] 
Eight responses were received from this group of MMET program constituencies. The survey showed that there were six companies that would hire draftsmen, and all eight companies would hire mechanical designers. SNL's current hiring strategy emphasizes mechanical designers with $\mathrm{BS}$ or MS degrees rather than the historic emphasis on designers with associate degrees. While it is clear that the degree does not make a designer great, the fundamentals gained through engineering and technology program are absolutely critical to full utilization of current computer tools and understanding of the design problems and solutions.

Table 1. Mechanical design survey results

\begin{tabular}{|c|c|c|c|c|c|c|}
\hline \multirow{2}{*}{ Subject } & \multicolumn{5}{|c|}{ Strength Level } & \multirow{2}{*}{$\begin{array}{l}\text { Total } \\
\text { Score }\end{array}$} \\
\hline & 5 & 4 & 3 & 2 & 1 & \\
\hline Engineering graphics & 7 & 1 & & & & 39 \\
\hline Dimensioning and tolerance & 7 & 1 & & & & 39 \\
\hline Computer-aided design software & 6 & 2 & & & & 38 \\
\hline Mechanics: Statics and dynamics & 3 & 2 & 2 & 1 & & 31 \\
\hline Strength of materials & 3 & 2 & 2 & 1 & & 31 \\
\hline Kinematics & 1 & 1 & 2 & 3 & 1 & 22 \\
\hline Load and stress analysis, failure theory & 2 & 2 & 2 & 2 & & 28 \\
\hline Finite element analysis & & 3 & 2 & 1 & 2 & 22 \\
\hline Machine elements (gears, bolts, springs, etc.) & 3 & 3 & 1 & 1 & & 32 \\
\hline Fluid mechanics and fluid power & 1 & & 2 & 3 & 1 & 18 \\
\hline Thermodynamics & & 1 & 3 & 2 & 2 & 19 \\
\hline Manufacturing processes & 3 & 2 & & 3 & & 29 \\
\hline Engineering materials & 1 & 5 & 1 & 1 & & 30 \\
\hline Project management & 1 & 3 & 2 & 1 & 1 & 26 \\
\hline \multicolumn{7}{|l|}{ Others/comments } \\
\hline Mechanical aptitude & 1 & & & & & 5 \\
\hline Basic computer operation & & 1 & & & & 4 \\
\hline Spreadsheets/word processors & & & 1 & & & 3 \\
\hline
\end{tabular}

In a simplistic view, design is to create geometry and select material to meet the functional requirements. The survey result show that the basic skills in understanding and creating geometry (engineering graphics, GD\&T, CAD software) ranked high receiving scores of 39, 39 and 38 points, respectively. Knowledge required for materials selection (engineering materials) ranks relatively high with 30 total points. Also highly ranked is the course in machine elements with 32 points. It cannot be interpreted that there is a lack of interest in the subjects with lower scores (such as kinematics, FEA, fluid mechanics and power and thermodynamics). Rather, it is believed that lower scores are due to: 1) an indirect correlation between subject matter and core products of the IAC member companies (e.g., if there was a machinery company, kinematics would rank high); or 2) engineers (e.g., FEA analysts and HVAC engineers) other than mechanical designers being hired to perform tasks that require specific expertise in the field. 
It can be seen that each subject listed in Table 1 does not necessarily correspond to a particular course shown in Figure 1. For example, there is no specific course for GD\&T. CAD software can be taught in different levels. Metallic and nonmetallic materials are commonly taught in two distinct courses. In the MMET program at TAMU, several manufacturing courses are offered to cover a wide spectrum of manufacturing processes. It can also be observed that the subjects are neither isolated nor simply related by prerequisites. While students learn mechanics to identify loading condition for stress analysis, critical skill in engineering graphics and CAD is required to create models and produce drawings to complete the design tasks. Therefore, integrating these subjects to better prepare students with the knowledge and skill required for mechanical design is critical to the success of the MMET program. While the existing curriculum provides the integrating experience in the capstone design course, it is clear that engaging students in critical thinking and design problem solving in an earlier stage while addressing the interdependencies of the coursework will greatly enhance student learning.

\section{Continuous Improvement of Mechanical Design Curriculum}

Preparing students with critical thinking and problem-solving skill is a primary objective of design education. Critical thinking can be seen as having two components: 1) a set of information generating and processing skills, and 2) the habit, based on intellectual commitment, of using those skills to guide behavior [10]. Design problem solving involves students' cognitive development. Through design problem solving, the students are exposed to multiplicity. They start to see that there is no standard solution and there can be more than one answer to a problem [11].

To engage students in critical thinking and problem solving, the interface of the subjects in various courses should be emphasized. Figure 3 presents a holistic view of the design curriculum.

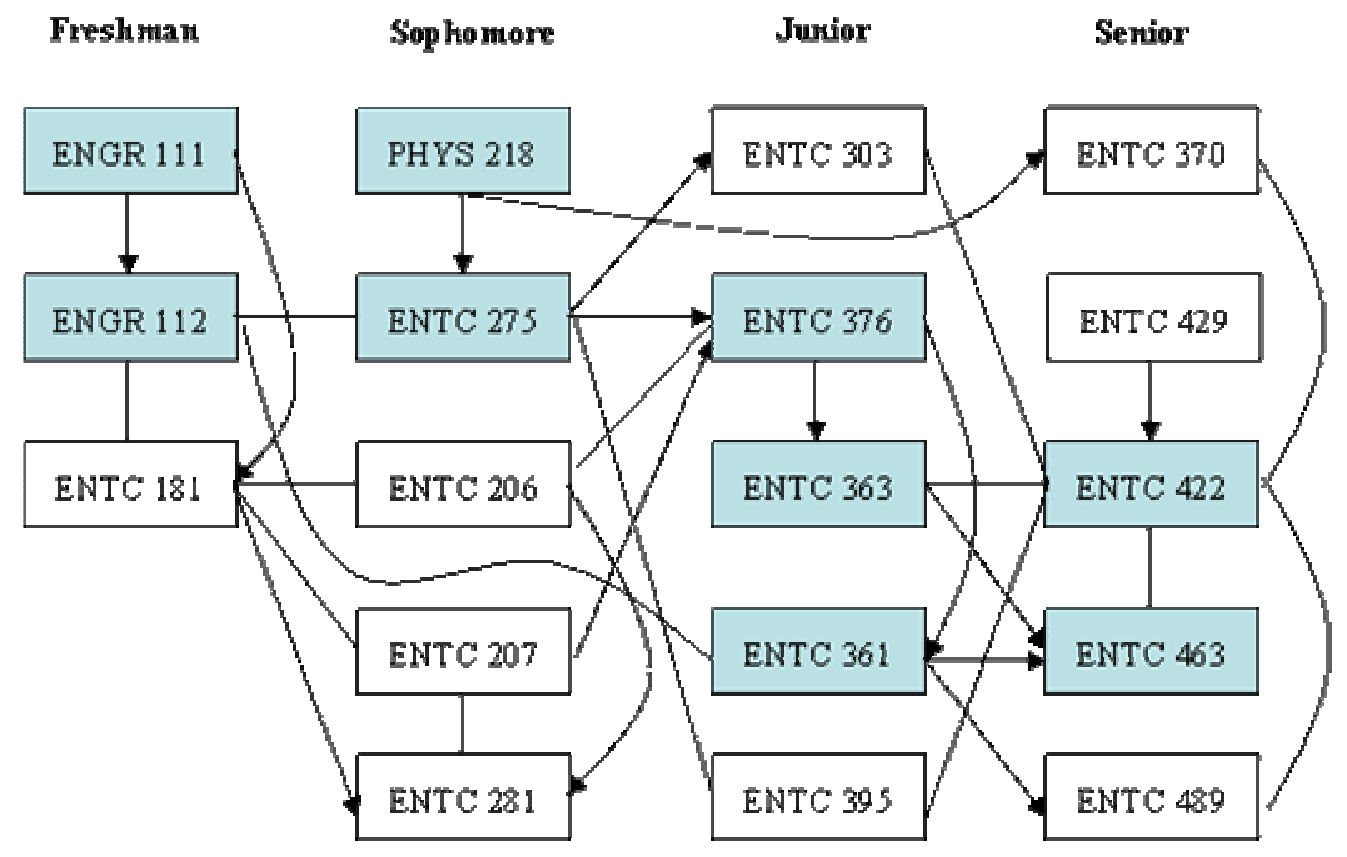

Figure 3 A holistic view of the mechanical design technical area 
In addition to the courses shown in Figure 1, the following courses can enhance students' knowledge and skill in design. These courses are mostly in materials, manufacturing processes, and fundamentals in mechanical engineering technology:

- ENTC 181 Manufacturing and Assembly Processes I

- ENTC 206 Nonmetallic Materials

- ENTC 207 Metallic Materials

- ENTC 281 Manufacturing and Assembly Processes II

- ENTC 303 Fluid Mechanics and Power

- ENTC 395 Electro-Mechanical Systems for Technologists

- ENTC 370 Thermodynamics for Technologists

- ENTC 429 Managing People and Projects

- $\quad$ ENTC 489 Special Topics in (Finite Element Analysis)

Arrows in Figure 3 represent prerequisites, and links without arrows indicate opportunities for improving the interface. Based on this holistic view, three types of action are recommended to improve the mechanical design education in the MMET program.

\section{$\underline{\text { Integrating Course Materials }}$}

One of the mechanisms to strengthen knowledge and skill in design is to provide the opportunities for introducing (previewing) and review course materials. This can be achieved by carefully designing lectures, homework assignments, and exams. The links between courses shown in Figure 3 present such opportunities. For example:

- In the mechanics course, the instructor can introduce the concept of stress after solving a free-body-diagram (identifying loads). In the strength of material course, students can be given appropriate homework problems to review mechanics.

- In teaching finite element analysis, problems can be designed for students to solve by hand calculation and by FEA software. As show in Figure 4, the displacement of the Lshape square bar at the end (where the load is applied) can be estimated through bending and torsion calculation. With the ability to estimate, students would better understand the finite element analysis results.

- Geometric dimensioning and tolerancing can be introduced in manufacturing processes courses to address the process capability issues. While it is taught in engineering graphics and CAD courses, it should also be integrated into design courses where tolerance and fit is critical to inspection and assembly.

- In machine design courses, team projects could be assigned that would utilize project management and team-building skills. 
Integrating course materials requires faculty collaboration to discover and capitalize on opportunities. In the MMET program, efforts are being made to address the integration issues in ENTC 376, ENTC 361, ENTC 363, and ENTC 463.

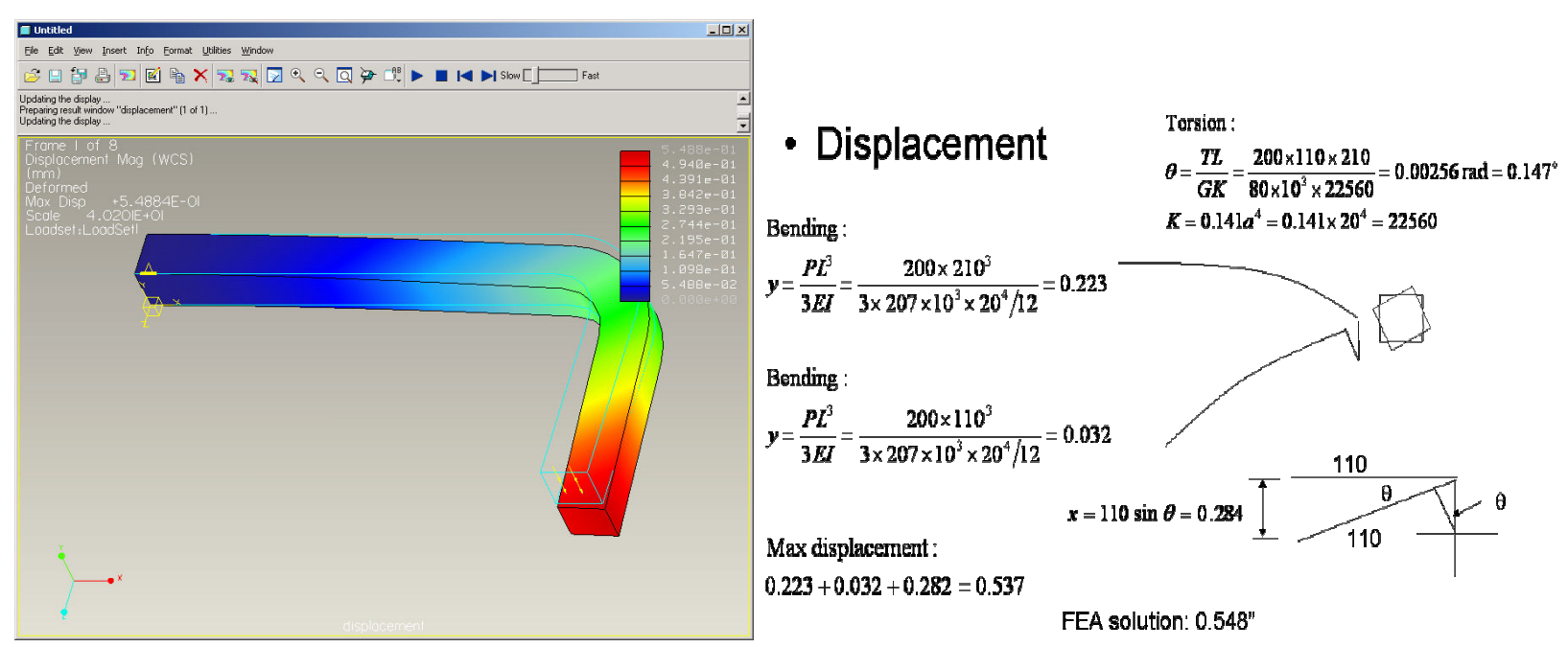

Figure 4 Finite element analysis vs. hand calculation

\section{Engaging Students in Design}

In engineering, technology, and physical science, most undergraduate courses are taught in a dualistic mode (there is a right and a wrong) [11]. With no standard solution for a design problem, frequently engaging students in design can help students to make the transition to multiplicity. Exposure to design practices will also improve students' decision making and CAD skills. For example:

- In the strength of material course, given cross-section geometry, applied axial force and material properties, students can calculate stress and determine if the part will fail. To engage students in design, the problem can be reformulated. Given only the applied load, students then have to come up with the cross section geometry and the material properties to satisfy the loading condition.

- In the machine element course, homework or projects can be assigned that require CAD tools to model a machine element, a sub-assembly or a commercial product. The exercises will give students opportunities to refresh their modeling skills.

Through changes in the teaching method, design-based learning is currently implemented in ENTC 363 and ENTC 463. Assignments are also given in ENTC 463 for students to perform reverse engineering of commercial products to enhance students' CAD skill. The design-based learning methodology is applicable to other courses, such as ENTC 361, ENTC 303, and ENTC 395.

$\underline{\text { Revising Mechanical Design Curriculum }}$ 
While integrating course materials and making changes in teaching methods can be implemented within a course, significant revision of course contents requires new efforts in curriculum design and development. Two major findings from the TAMU-SNL project and the IAC survey prompt the initiative to recommend curriculum change: 1 ) students are expected to have a strong background in engineering graphics, be proficient in CAD tools, and have a thorough understanding of GD\&T; 2) instead of only modeling and drafting, future mechanical designers are expected to perform design tasks that require in-depth knowledge and skill in certain technical areas. In response to the findings, two suggested changes are being developed:

- Currently, AutoCAD, Pro/ENGINEER and SolidWorks are taught / used in various courses in the Department and in the College of Engineering. While acquiring different CAD skills may sound positive, the students do not have sufficient time to explore all the functionalities of these state-of-the-art CAD tools in order to become proficient. Therefore, the MMET program has selected Pro/E as a primary CAD tool. Without the burden of learning new CAD tools in various courses, students will have more time to focus on course materials. The recommended change could affect all the courses that require students to produce models and drawings for homework assignments and projects.

- It is suggested that the MMET Program offer technical electives to enhance students' mechanical design skill and knowledge. The technical electives can be an advanced special topic (ENTC 489 in Figure 3) that is of interest to student and faculty. For example, the solid modeling and finite element analysis are currently taught in ENTC 361. The time required for students to learn the modeling tools and pre-processing techniques prevents a more in-depth learning of finite element method. Thus, offering $\mathrm{CAD} /$ solid modeling and finite element analysis topics in separate courses is suggested. Other technical electives that may be of interest to MMET students include: kinematics, tooling design, design of fluid power systems, design of energy systems, design of electro-mechanical systems, and design for manufacturing and assembly.

The results of the review and the suggested actions (including curriculum change) are being discussed among faculty members who are teaching mechanical design courses. An assessment plan is being prepared to provide feedback for future improvement.

\section{Conclusions}

The objective of the mechanical design course is to provide students the concepts, knowledge, methodologies, analytical skills, and decision making techniques necessary to design mechanical parts, devices, and systems. Therefore, mechanical design is a critical component in the manufacturing and mechanical engineering technology education. This paper presents a curriculum review and development effort in the MMET program at Texas A\&M University. Based on the experience from a professional development program at Sandia National Laboratories and the survey of the MMET Industry Advisory Committee, it is clear that students must acquire enhanced knowledge and skill prior to graduation. The desired skill outcome in the area of mechanical design was identified. As there is no direct mapping between the desired outcomes and the MMET courses, it is believed that integrating design-related subjects can better 
prepare students for future challenges. While the existing curriculum provides students an integrating experience in the capstone design course, it is clear that engaging students in critical thinking and design problem solving in an earlier stage will greatly enhance student learning. Based on the holistic view of mechanical design curriculum, the paper presents three different mechanisms to improve the existing design curriculum. The improvement of student learning can be assessed through the established ABET feedback mechanism. These assessment tools include graduate exit survey, faculty course evaluation, exit exam, and IAC evaluation. The methodology presented in this study can be used as a continuous improvement process for engineering technology education.

\section{Acknowledgement}

The authors would like to thank Sandia National Laboratories for the support of the TAMUSandia professional development project described in this paper. Sandia is a multi-program laboratory operated by Sandia Corporation, a Lockheed Martin Company for the United States Department of Energy's National Nuclear Security Administration under contract DE-AC0494AL85000.

\section{References}

1. Shigley, J. E., Mischke, C. R., and Budynas, R. G., Mechanical Engineering Design, $7^{\text {th }}$ Ed., McGraw Hill, 2004.

2. Bachnak, R., Verma, S., and Coppinger, T., "Restructuring the Capstone Course Leads to Successful Projects," Proceedings of the 2005 ASEE Annual Conference and Exposition, Section 1647, June 2005.

3. Burbank, K., Holcomb, J., Cooper-Duffy, K., and Prohn, JK., “A Wheelchair Navigation System as a Collaborative Senior Project," Proceedings of the 2005 ASEE Annual Conference and Exposition, Section 1347, June 2005.

4. Chen, I.-M., Xing, S., Tay, R., and Yeo S. H., "Many Strings Attached, From Conventional to Robotic Marionette Manipulation,” IEEE Robotics \& Automation Magazine, pp. 59-73, March 2005.

5. Dobson, R., Kowalski, K., Ostermann, S., Pittenger, J., and Tiller, W., Marionette Prototype Design Final Report, Department of Engineering Technology and Industrial Distribution, Texas A\&M University, May 2005.

6. Mirman, C. R., “An Engineering Technology Capstone Course which Integrates Theory, Design, and Construction in an Open-Ended Project," Proceedings of the 2005 ASEE Annual Conference and Exposition, Section 1648, June 2005.

7. Morgan, J. A., Wright, G., and Porter, J. R., "Managing Senior Design Projects to Maximize Success: The TAT Team," Proceedings of the 2005 ASEE Annual Conference and Exposition, Section 1347, June 2005.

8. Wang, J., Liu, S., and Price, A. "The Dancing Marionette - An Interdisciplinary Capstone Design Experience for Engineering Technology and Computer Science Students, Proceedings of 2006 ASEE Annual Conference and Exposition, June 2006. 
9. Self-Study Report, Manufacturing and Mechanical Engineering Technology Program, Department of Engineering Technology and Industrial Distribution, Texas A\&M University, June 15, 2006.

10. http://www.criticalthinking.org/aboutCT/definingCT.shtml (date accessed January 10, 2007)

11. Wankat, P. C., The Effective, Efficient Professor - Teaching, Scholarship and Service, Allyn and Bacon, 2002 